\title{
Correction to: Support for COVID-19- Related Substance Use Services Policy Changes: a New York State-Wide Survey
}

\author{
Amar D. Mandavia $\odot$, MA \\ Aimee Campbell, PhD \\ Brandy F. Henry, PhD
}

\begin{abstract}
The original article can be found online at https://doi.org/10.1007/s11414-021-09784-y
Address correspondence to Amar D. Mandavia Department of Counseling and Clinical Psychology, Teachers College, Columbia University, 525 West 120th Street, New York, NY, 10027, USA. adm2183@tc.columbia.edu.

Aimee Campbell, Department of Psychiatry, Columbia University Irving Medical Center, New York, NY, USA.

Michael Chaple, Department of Psychiatry, Columbia University Irving Medical Center, New York, NY, USA.

Harold A. Pincus, Department of Psychiatry, Columbia University Irving Medical Center, New York, NY, USA.

Edward V. Nunes, Department of Psychiatry, Columbia University Irving Medical Center, New York, NY, USA.

Frances R. Levin, Department of Psychiatry, Columbia University Irving Medical Center, New York, NY, USA.

adm2183@tc.columbia.edu.

Aimee Campbell, New York State Psychiatric Institute in the Division On Substance Use Disorders, New York, NY, USA.

Caroline Arout, New York State Psychiatric Institute in the Division On Substance Use Disorders, New York, NY, USA.

Harold A. Pincus, New York State Psychiatric Institute in the Division On Substance Use Disorders, New York, NY, USA.

Edward V. Nunes, New York State Psychiatric Institute in the Division On Substance Use Disorders, New York, NY, USA.

Frances R. Levin, New York State Psychiatric Institute in the Division On Substance Use Disorders, New York, NY, USA.

Brandy F. Henry, Social Intervention Group, Columbia University School of Social Work, New York, NY, USA. Timothy Hunt, Social Intervention Group, Columbia University School of Social Work, New York, NY, USA.

Elwin Wu, Social Intervention Group, Columbia University School of Social Work, New York, NY, USA.

Nabila El-Bassel, Social Intervention Group, Columbia University School of Social Work, New York, NY, USA.

Pat Lincourt, New York State Office of Addiction Services and Supports, Albany, NY, USA.
\end{abstract}

The Journal of Behavioral Health Services \& Research, 2022. 414-415. @ 2022, National Council for Mental Wellbeing,. DOI 10.1007/s11414-022-09793-5 


\section{Michael Chaple, PhD}

Timothy Hunt, PhD

Caroline Arout, PhD

Elwin Wu, PhD

Harold A. Pincus, MD

Edward V. Nunes, MD

Pat Lincourt, MSW

Frances R. Levin, MD

Nabila El-Bassel, PhD

\section{Correction to: J Behav Health Serv Res}

https://doi.org/10.1007/s11414-021-09784-y

The second to last name in the author list has an error. The author's first name should be spelled "Frances" instead of "Francis".

Publisher's Note Springer Nature remains neutral with regard to jurisdictional claims in published maps and institutional affiliations. 